\title{
Gastric Electrical Stimulation Is an Effective Treatment Modality for Refractory Gastroparesis in a Postsurgical Patient with Pancreatic Cancer
}

\author{
Shreyans Doshid, e Aniruddh Patel ${ }^{a} \quad$ Abigail Stocker $^{a}$ \\ Charles Scoggins $^{b} \quad$ Laila Agrawal $^{c}$ Thomas Abell ${ }^{a}$
}

aDivision of Gastroenterology, Hepatology and Nutrition, Department of Medicine, University of Louisville, Louisville, KY, USA; ${ }^{b}$ Division of Surgical Oncology, Department of Surgery, University of Louisville, Louisville, KY, USA; 'Division of Hematology and Oncology, Department of Medicine, University of Louisville, Louisville, KY, USA; dUniversity of Central Florida College of Medicine, Graduate Medical Education, Orlando, FL, USA; eNorth Florida Regional Medical Center, Internal Medicine Residency Program, Gainesville, FL, USA

\section{Keywords}

Gastric electrical stimulation · Gastroparesis · Pancreatic cancer · Whipple surgery

\begin{abstract}
Gastroparesis-related hospital visits contribute significantly to healthcare costs. Gastroparesis can lead to chronic symptoms, such as nausea, vomiting, bloating, early satiety, and abdominal pain. It can result in a significant impairment of quality of life. Diabetes and postsurgery are common causes for gastroparesis, but most cases of gastroparesis are idiopathic in presumed etiology. Malignancy-related gastroparesis has also recently been described in the literature, and pancreatic cancer is a malignancy commonly associated with gastroparesis. Whipple surgery for pancreatic cancer is often complicated by gastroparesis during its postoperative
\end{abstract}




\section{Case Reports in Gastroenterology}

Case Rep Gastroenterol 2019;13:430-437

DOI: $10.1159 / 000503275$

(c) 2019 The Author(s). Published by S. Karger AG, Base www.karger.com/crg

Doshi et al.: Gastric Electrical Stimulation Is an Effective Treatment Modality for

Refractory Gastroparesis in a Postsurgical Patient with Pancreatic Cancer

course. We report a case where gastric electrical stimulation was an effective treatment option in the treatment of refractory malignancy-related gastroparesis.

(C) 2019 The Author(s)

Published by S. Karger AG, Basel

\section{Introduction}

Gastroparesis (GP) is a motility disorder typically characterized by delayed gastric emptying in the absence of mechanical obstruction. Typical symptomatology includes nausea, vomiting, bloating, early satiety, and abdominal pain [1]. If left untreated, chronic GP can result in significant morbidity and mortality [2]. Gastric electrical stimulation (GES) has been proven to be beneficial for drug-refractory GP, but permanent GES (PERM) requires surgery. Temporary GES electrodes placement via endoscope (ENDOstim) or via a percutaneous endoscopic gastrostomy (PEG) (PEGstim) is easier and can predict improvement in GP symptoms with PERM implantation [3, 4]. Postsurgical GP, particularly following Whipple procedure for pancreatic cancer, has been well documented in the literature [5]. Here, we present a case of GP in a patient with pancreatic cancer status after Whipple surgery that was successfully treated with GES.

\section{Case Presentation}

A 72-year-old male with a history of diabetes mellitus type II, hypertension, cerebrovascular accident, and ulcerative colitis status post total proctocolectomy with J-pouch creation was sent to hospital by his primary care physician for jaundice and severe itching. He presumably had cancer of the pancreatic head sized $1.8 \mathrm{~cm}$ according to CT imaging. An endoscopic retrograde cholangiopancreatography revealed an irregular stricture within the pancreatic duct, which was opened with a stent placement. There was also a hypoechoic, well-circumscribed, irregularly shaped mass seen during endoscopic ultrasound measuring 2.9 by $3.9 \mathrm{~cm}$. Fine-needle aspiration showed atypical cells with a possible mucinous neoplastic or dysplastic process. The patient was scheduled for a Whipple procedure after no evidence of metastatic disease was found on repeat MRI. The patient underwent an exploratory laparotomy along with extensive adhesion lysis $(2 \mathrm{~h})$, pancreaticoduodenectomy, retroperitoneal and portal lymphadenectomy, and open jejunostomy tube (J tube) placement. Final pathology from surgery confirmed moderately differentiated invasive ductal adenocarcinoma measuring $3.5 \mathrm{~cm}$ and involving the pancreatic head, neck parenchyma, peripancreatic fibroadipose tissue, and 12 out of 27 lymph nodes without perineural invasion (Fig. 1, Fig. 2, Fig. 3).

The patient's postoperative course was complicated by nausea, vomiting, and abdominal pain. On postoperative day (POD) 1, he developed uncontrolled hyperglycemia which required insulin drip. He also received narcotics for uncontrolled postoperative pain. He was on hydrocodone/paracetamol 7.5/750 mg 3 times daily as needed for cervical radiculopathy and also received hydromorphone and oxycodone in the perioperative period for pain. He was started on tube feeds via the J tube; however, he developed pneumatosis intestinalis and was started on total peripheral nutrition on POD 8 with no enteral intake due to high nasogastric 


\section{Case Reports in Gastroenterology} \begin{tabular}{l|l} 
Case Rep Gastroenterol 2019;13:430-437 \\
\hline DOI: 10.1159/000503275 & $\begin{array}{l}\text { @ 2019 The Author(s). Published by S. Karger AG, Basel } \\
\text { www.karger.com/crg }\end{array}$
\end{tabular}

Doshi et al:: Gastric Electrical Stimulation Is an Effective Treatment Modality for

Refractory Gastroparesis in a Postsurgical Patient with Pancreatic Cancer

tube output. Ondansetron, erythromycin ( $300 \mathrm{mg}$ every $8 \mathrm{~h}$ ), and metoclopramide (5 mg intravenous every $6 \mathrm{~h}$ ) were used for symptomatic treatment. Metoclopramide was discontinued due to tachycardia and QTc prolongation on electrocardiogram. Erythromycin and ondansetron were used as needed. He improved clinically within the next few days and underwent an esophagogastroduodenoscopy (EGD)-PEG placement for decompression, with EGD findings of semisolid food content concerning for GP. He was discharged 2 weeks after surgery with a G-J tube while he was tolerating J-tube feeding. The patient was readmitted 4 days later for severe dehydration and high G-tube output ( $\sim 4$ L every $24 \mathrm{~h}$ ). Gastroenterology was consulted for management as the patient reported severe nausea, early satiety, bloating, and abdominal pain as shown in Table 1, and all the symptoms were refractory to glucose control and prokinetic and antiemetic agents.

A radionuclide gastric emptying study demonstrated delayed emptying of liquids (while still taking narcotics). He underwent a temporary stimulator placement on POD 26 via nasal access to the lead wires with the following settings ( $8 \mathrm{~V}, 330 \mu \mathrm{s} \mathrm{PW}, 14 \mathrm{~Hz}, 1 \mathrm{~s}$ on, $4 \mathrm{~s}$ off) (Fig. 4). A standard upper gastroscope was used and an external Medtronic Enterra II stimulator with the size of $6.0 \times 5.5 \times 1.14 \mathrm{~cm}$ and $45 \mathrm{~g}$ weight was placed. The patient underwent an EGD with the goal of switching lead access from nasal to PEG tube due to nasal discomfort from leads. His G-tube output had markedly decreased from $4 \mathrm{~L}$ on admission to $1.9 \mathrm{~L}$ by POD 35. The symptoms score improved after placement of the temporary stimulator via nasal access and remained stable after changing the lead access (Table 1).

He was discharged home with J-tube feeds and full liquid diet for comfort. The patient's symptoms scores improved dramatically with the placement of the gastric electrical stimulator. He was seen in the gastrointestinal motility clinic on POD 61, at which time he reported complete resolution of his postsurgical upper abdominal symptoms (Table 1).

His temporary stimulator was turned off during this clinic visit, and his external GES device was disconnected with removal of the leads on POD 86. The patient reported no recurrence of symptoms when contacted on POD 89 (Table 1). Follow-up 6 months later revealed that he was doing well and tolerating chemotherapy.

\section{Discussion}

GP is a complex syndrome caused by delayed gastric emptying in the absence of mechanical obstruction. It can lead to chronic nausea, vomiting, electrolyte disturbances, dehydration, and hospitalization. The majority of cases are idiopathic, followed by diabetic and postsurgical cases [6]. Malignancy-associated GP is also described in a few studies and is widely associated with advanced pancreatic cancer [7]. The pathogenesis of GP includes direct tumor infiltration of the nerves, gastrointestinal surgery-related decreased motilin hormone, as well as vagotomy. Immune-mediated destruction of the interstitial cells of Cajal is one of the proposed mechanisms [8]. Gastric scintigraphy following a liquid and solid meal is a standardized test for delayed gastric emptying [9]. Treatment options are guided by symptom severity. Dietary and behavioral modifications followed by prokinetics and antiemetics are the mainstay of therapy [1]. If symptoms do not respond to dietary changes, glucose control, narcotic elimination, prokinetics, and antiemetics, then patients are considered as refractory cases. For refractory cases, a GES device may be considered [10,11]. Abell et al. [12] demonstrated a significant 
postoperative increase in the physical and mental component scores, and a few studies [13, 14] also noted a significant increase in quality of life. Typically, complications of GES occur in $5-14 \%$ of patients, including infection of the pulse generator site and migration and erosion of the stimulating device [15].

Here, we reported a case of severe GP in a patient with pancreatic cancer status post Whipple surgery. Pancreatic leak, hemorrhage, intraabdominal abscess, and delayed gastric emptying are the most common complications of Whipple surgery. GP has emerged as the leading procedure-related morbidity [16-18]. Although there have been technical advances, there is a lack of universal standardized surgical techniques for pancreaticoduodenectomy [19]. Postsurgical delayed gastric emptying was reported in up to $50 \%$ of patients in the early postoperative period. Usually, the treatment options for postsurgical GP are dietary modification, medications for symptomatic relief, acupuncture, and a venting gastrostomy or a jejunostomy. These treatment options are limited for initial treatment and may not be effective for refractory postoperative GP, whose true incidence is unknown [20], and such cases may take up to 6 months for recovery [21]. Severe cases of postoperative GP have been reported and have very limited options for symptom relief. GES has led to great symptom relief in severe refractory postoperative GP cases $[22,23]$. There is 1 case report of successful minimally invasive thoracoscopic implant of a GES system for gastric conduit GP after esophagectomy [24]. Based on this case, GES for refractory GP, delivered in a temporary manner, may be useful in patients with pancreatic cancer having Whipple surgery-associated GP.

\section{Acknowledgements}

The authors would like to thank the staff of Norton Hospital GI Lab as well as the Jewish Hospital/ULP GI Motility Clinic for help with the patients. They want to thank John Williamson for assistance with anatomical images and Catherine McBride for help with manuscript preparation.

\section{Statement of Ethics}

This case was covered under an existing IRB protocol at the University of Louisville.

\section{Disclosure Statement}

Dr. Abell is the founder of ADEPT-GI, which has intellectual property of some of the technology used in this article.

\section{Funding Sources}

There was no funding. 


\section{Case Reports in Gastroenterology}

Case Rep Gastroenterol 2019;13:430-437

DOI: $10.1159 / 00050327$

(C) 2019 The Author(s). Published by S. Karger AG, Base www.karger.com/crg

Doshi et al: Gastric Electrical Stimulation Is an Effective Treatment Modality for

Refractory Gastroparesis in a Postsurgical Patient with Pancreatic Cancer

\section{Author Contributions}

Shreyans Doshi: Concept, data acquisition, data analysis, final approval of manuscript. Aniruddh Patel: Concept, data acquisition, data analysis, final approval of manuscript. Abigail Stocker: Concept, data acquisition, final approval of manuscript. Charles Scoggins: Data acquisition, final approval of manuscript. Laila Agrawal: Data acquisition, final approval of manuscript. Thomas Abell: Concept, data acquisition, data analysis, final approval of manuscript.

\section{References}

1 Camilleri M, Parkman HP, Shafi MA, Abell TL, Gerson L; American College of Gastroenterology. Clinical guideline: management of gastroparesis. Am J Gastroenterol. 2013 Jan;108(1):18-37; quiz 38

2 Parkman HP, Schwartz SS. Esophagitis and gastroduodenal disorders associated with diabetic gastroparesis. Arch Intern Med. 1987 Aug;147(8):1477-80.

3 Daram SR, Tang SJ, Abell TL. Video: temporary gastric electrical stimulation for gastroparesis: endoscopic placement of electrodes (ENDOstim). Surg Endosc. 2011 Oct;25(10):3444-5.

4 Ayinala S, Batista O, Goyal A, Al-Juburi A, Abidi N, Familoni B, et al. Temporary gastric electrical stimulation with orally or PEG-placed electrodes in patients with drug refractory gastroparesis. Gastrointest Endosc. 2005 Mar;61(3):455-61.

5 Riediger H, Makowiec F, Schareck WD, Hopt UT, Adam U. Delayed gastric emptying after pylorus-preserving pancreatoduodenectomy is strongly related to other postoperative complications. J Gastrointest Surg. 2003 Sep-Oct; 7(6):758-65.

6 Soykan I, Sivri B, Sarosiek I, Kiernan B, McCallum RW. Demography, clinical characteristics, psychological and abuse profiles, treatment, and long-term follow-up of patients with gastroparesis. Dig Dis Sci. 1998 Nov;43(11):2398-404.

7 Barkin JS, Goldberg RI, Sfakianakis GN, Levi J. Pancreatic carcinoma is associated with delayed gastric emptying. Dig Dis Sci. 1986 Mar;31(3):265-7.

8 Angeli TR, Cheng LK, Du P, Wang TH, Bernard CE, Vannucchi MG, et al. Loss of Interstitial Cells of Cajal and Patterns of Gastric Dysrhythmia in Patients with Chronic Unexplained Nausea and Vomiting. Gastroenterology. 2015 Jul;149(1):56-66.e5.

9 Kelly D, Moran C, Maher M, O'Mahony S. Malignancy-associated gastroparesis: an important and overlooked cause of chronic nausea and vomiting. BMJ Case Rep. 2014 Feb;2014. pii: bcr2013201815.

10 Shah H, Wendorf G, Ahmed S, McElmurray L, Lahr C, Hughes M, et al. Treating an oft-unrecognized and troublesome entity: using gastric electrical stimulation to reduce symptoms of malignancy-associated gastroparesis. Support Care Cancer. 2017 Jan;25(1):27-31.

11 Wendorf G, Mehta M, Stocker A, Smith J, Abell T. Endoscopic aspects of temporary gastric electrical stimulator lead placement in patients with gastroparesis and gastroparesis-like syndromes. VideoGIE. 2018 Apr;3(4):112.

12 Abell T, Lou J, Tabbaa M, Batista 0, Malinowski S, Al-Juburi A. Gastric electrical stimulation for gastroparesis improves nutritional parameters at short, intermediate, and long-term follow-up. JPEN J Parenter Enteral Nutr. 2003 Jul-Aug;27(4):277-81.

13 McCallum RW, Snape W, Brody F, Wo J, Parkman HP, Nowak T. Gastric electrical stimulation with Enterra therapy improves symptoms from diabetic gastroparesis in a prospective study. Clin Gastroenterol Hepatol. 2010 Nov;8(11):947-54.

14 McCallum RW, Sarosiek I, Parkman HP, Snape W, Brody F, Wo J, et al. Gastric electrical stimulation with Enterra therapy improves symptoms of idiopathic gastroparesis. Neurogastroenterol Motil. 2013 Oct;25(10):815-e636.

15 Lal N, Livemore S, Dunne D, Khan I. Gastric Electrical Stimulation with the Enterra System: A Systematic Review. Gastroenterol Res Pract. 2015;2015:762972.

16 Yeo CJ, Cameron JL, Sohn TA, Lillemoe KD, Pitt HA, Talamini MA, et al. Six hundred fifty consecutive pancreaticoduodenectomies in the 1990s: pathology, complications, and outcomes. Ann Surg. 1997 Sep;226(3):248-57; discussion 257-60. 


\section{Case Reports in Gastroenterology}

\begin{tabular}{l|l}
\hline Case Rep Gastroenterol 2019;13:430-437 \\
\hline DOI: 10.1159/000503275 & $\begin{array}{l}\text { @ 2019 The Author(s). Published by S. Karger AG, Basel } \\
\text { www.karger.com/crg }\end{array}$ \\
\hline
\end{tabular}

Doshi et al:: Gastric Electrical Stimulation Is an Effective Treatment Modality for Refractory Gastroparesis in a Postsurgical Patient with Pancreatic Cancer

17 Büchler MW, Wagner M, Schmied BM, Uhl W, Friess H, Z'graggen K. Changes in morbidity after pancreatic resection: toward the end of completion pancreatectomy. Arch Surg. 2003 Dec;138(12):1310-4; discussion 1315.

18 Noorani A, Rangelova E, Del Chiaro M, Lundell LR, Ansorge C. Delayed Gastric Emptying after Pancreatic Surgery: Analysis of Factors Determinant for the Short-term Outcome. Front Surg. 2016 Apr;3:25.

19 Bandu R, Mok HJ, Kim KP. Phospholipids as cancer biomarkers: mass spectrometry-based analysis. Mass Spectrom Rev. 2018 Mar;37(2):107-38.

20 Dong K, Yu XJ, Li B, Wen EG, Xiong W, Guan QL. Advances in mechanisms of postsurgical gastroparesis syndrome and its diagnosis and treatment. Chin J Dig Dis. 2006;7(2):76-82.

21 Tanaka M. Gastroparesis after a pylorus-preserving pancreatoduodenectomy. Surg Today. 2005;35(5): 345-50.

22 McCallum R, Lin Z, Wetzel P, Sarosiek I, Forster J. Clinical response to gastric electrical stimulation in patients with postsurgical gastroparesis. Clin Gastroenterol Hepatol. 2005 Jan;3(1):49-54.

23 Salameh JR, Aru GM, Bolton W, Abell TL. Electrostimulation for intractable delayed emptying of intrathoracic stomach after esophagectomy. Ann Thorac Surg. 2008 Apr;85(4):1417-9.

24 Asti E, Lovece A, Bonavina L. Thoracoscopic Implant of Neurostimulator for Delayed Gastric Conduit Emptying After Esophagectomy. J Laparoendosc Adv Surg Tech A. 2016 Apr;26(4):299-301.

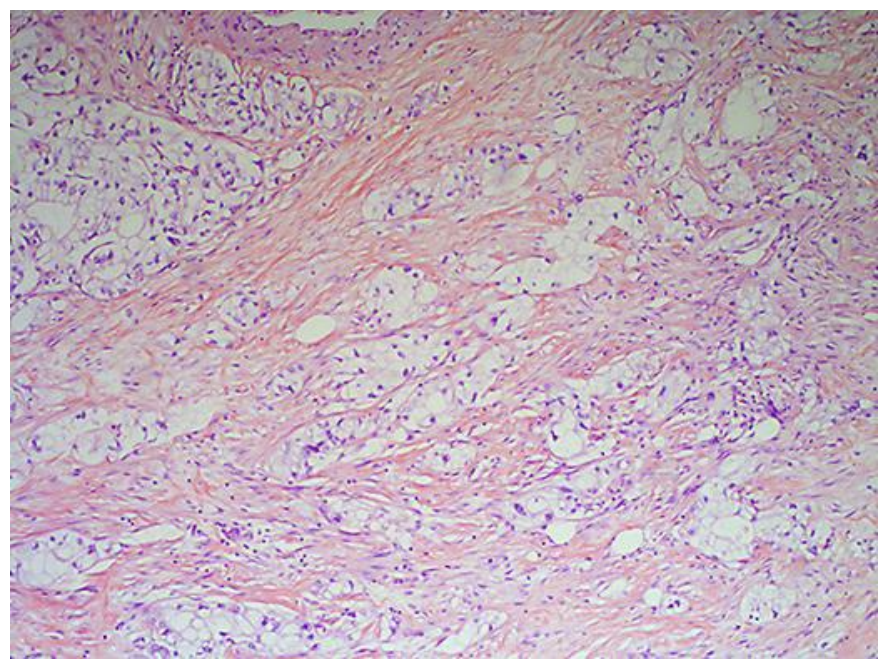

Fig. 1. Invasive adenocarcinoma of the pancreatic head. HE, $\times 100$. 


\section{Case Reports in Gastroenterology}

Case Rep Gastroenterol 2019;13:430-437

(c) 2019 The Author(s). Published by S. Karger AG, Basel www.karger.com/crg

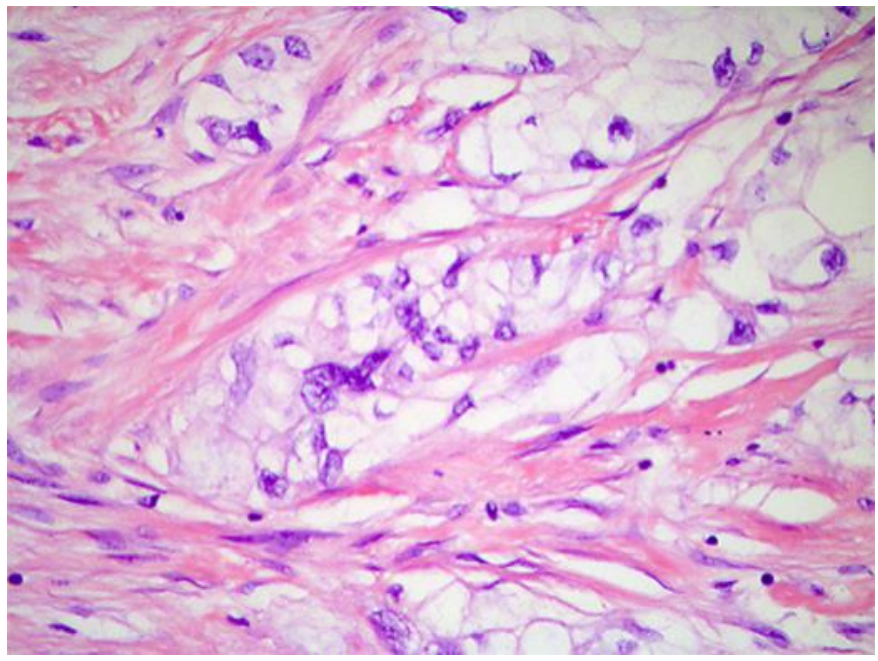

Fig. 2. Invasive adenocarcinoma of the pancreatic head. HE, $\times 400$.

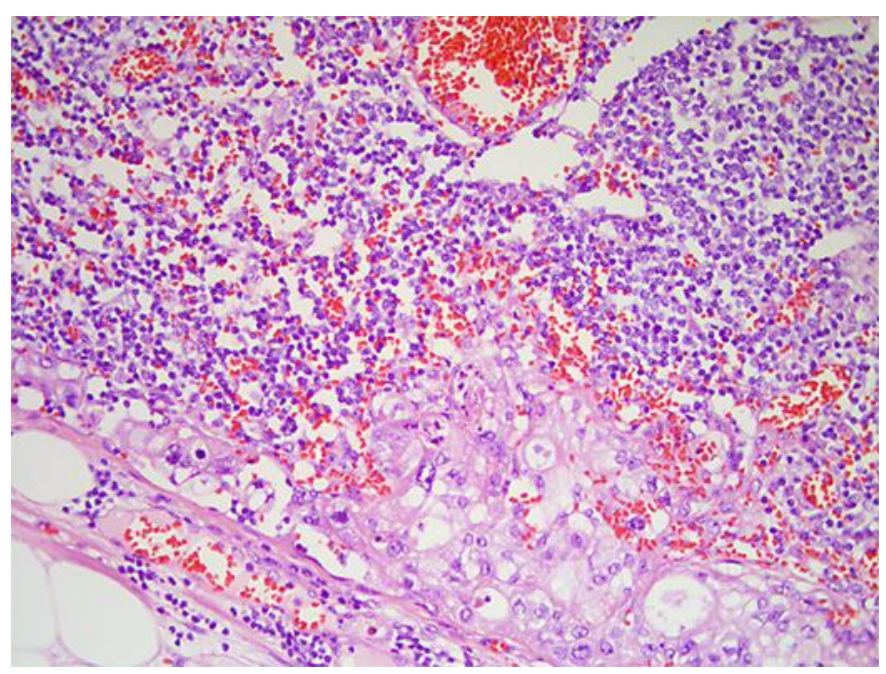

Fig. 3. Metastatic adenocarcinoma to the peripancreatic lymph node. HE, $\times 200$. 


\section{Case Reports in Gastroenterology}

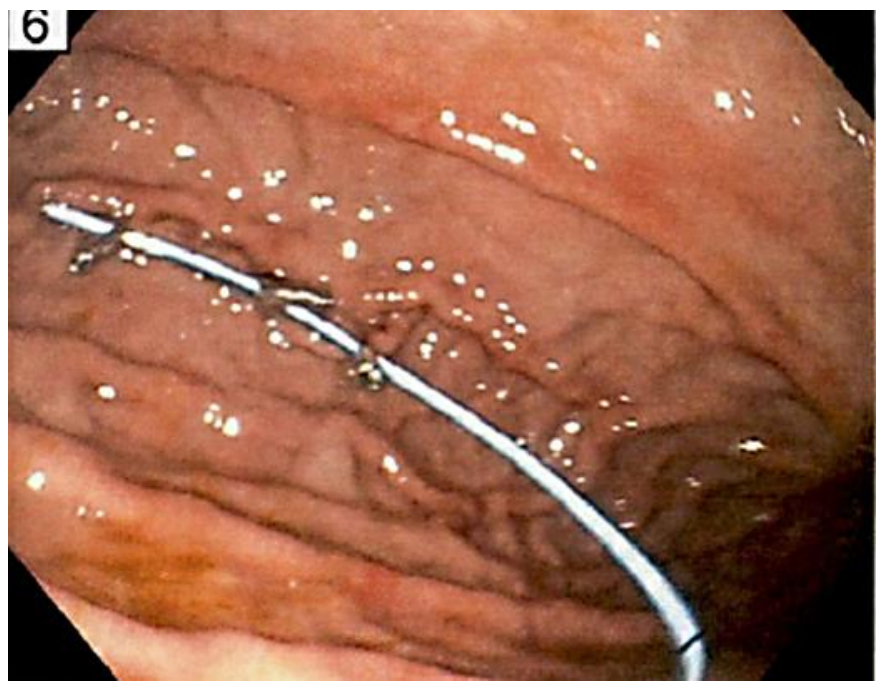

Fig. 4. Temporary GES lead is shown clipped against the gastric mucosa.

Table 1. Traditional patient-reported outcome scale

\begin{tabular}{llllllllll}
\hline & $\mathrm{A}$ & $\mathrm{B}-1$ & $\mathrm{~B}-2$ & $\mathrm{~B}-3$ & $\mathrm{C}$ & $\mathrm{D}$ & $\mathrm{E}$ & $\mathrm{F}$ & $\mathrm{G}$ \\
\hline Vomiting & 1 & 0 & 0 & 0 & 0 & 0 & 0 & 0 & 0 \\
Nausea & 4 & 0 & 1 & 0 & 1 & 0 & 0 & 0 & 0 \\
Feeling full quickly & 3 & 2 & 1 & 0 & 2 & 0 & 1 & 1 & 1 \\
Bloating & 3 & 2 & 1 & 0 & 2 & 0 & 0 & 0 & 0 \\
Abdominal pain & 4 & 1 & 0 & 1 & 1 & 0 & 2 & 1 & 1 \\
Diarrhea frequency & 4 & & & & 4 & & & 3 & 3 \\
Switched leads? & & & $\mathrm{Y}$ & & & & & &
\end{tabular}

A = Baseline symptoms score postoperative day (POD) 25 - Pretemporary stimulator placement, score 04: none to worse. $\mathrm{B}=$ Symptoms score after placement of temporary stimulator via nasal access. B-1 = POD 27. B-2 = Switched leads, POD 29. B-3 = POD 32. C = Symptoms score on the day of switching lead access, POD 35, temporary stimulator switched from nasal to PEG. D = Symptoms score after discharge to home with J-tube feeds and full liquid diet with stimulator, POD 42. E = Symptoms score with solid diet with stimulator, POD 49. F = Symptoms score with solid diet with stimulator turned off, POD 61. G = Symptoms score with solid diet with stimulator turned off, after a month - POD 89. 